Revista do Programa de Pós-Graduação em Mídia e Cotidiano

Artigo Seção Livre

Número 6. Volume 6 /Julho 2015

(C) 2015 by UFF

\title{
AVALIACÃO DO ENSINO DE ONLINE NO CURSO DE JORNALISMO: O OLHAR DO ESPECIALISTA, DA GESTORA E DOS EGRESSOS
}

\section{THE EVALUATION OF ONLINE JOURNALISM COURSE: the look of the specialist, manager and former students}

\section{Rosimeri Figueiredo de Matos TRISTÃOํㅜ ${ }^{1}$ Luci Mary Araújo HILDENBRAND²}

Resumo: O artigo expõe o estudo que se dispôs a avaliar o mérito e o impacto inicial da Disciplina Projeto de Jornalismo Online, do Curso de Jornalismo de uma faculdade, situada no Rio de Janeiro. As questões avaliativas relacionaram-se aos critérios utilizados na contratação de jornalistas online e às contribuições da Disciplina, tendo em vista a devida preparação do graduando para este mercado de trabalho. A avaliação apoiou-se nos fundamentos da abordagem proposta por Scriven e os indicadores considerados derivaram-se de análises de Figueiredo (2014) em relação ao Projeto Pedagógico, à grade curricular do Curso e à proposta pedagógica da Disciplina. Dentre as recomendações, destaca-se a possibilidade de o estudo contribuir para o debate acadêmico sobre a importância da Disciplina na formação profissional, contribuindo para a construção de um olhar acerca do online como mais uma modalidade dos Cursos de Jornalismo.

Palavras-chave: Avaliação de disciplina; mérito e impacto; jornalismo online.

Abstract: The article reflects the study evaluating the merit and the initial impact of Discipline Online Journalism Project, Journalism Course in Higher Institution, located in Rio de Janeiro. The evaluation questions related to the criteria used in hiring online journalists and the Discipline of the contributions for the preparation of graduates for the market, considering the curricular structure of the course. The assessment we used the fundamentals of the approach proposed by Scriven. The indicators derived from analysis of the Pedagogical Project of the Course, the curriculum and teaching of the discipline proposal, supported by teaching experience. The recommendations highlighted the possibility of the evaluation contribute to the academic debate about the importance of discipline in the training of professional journalism.

Keywords: discipline Assessment; Merit and impact; Online Journalism.

\footnotetext{
${ }^{1}$ Mestre em Avaliação pela Fundação Cesgranrio; Profa. de Jornalismo. rosedefigueiredo@gmail.com.

2 Profa Doutora; Docente no Curso de Mestrado Profissional em Avaliação da Fundação Cesgranrio,
} 


\section{míDiA

\section{INTRODUÇÃO}

O jornalismo transcendeu o ato de divulgar fatos, checar informações e ouvir mais de uma fonte para garantir a fidedignidade das matérias, com o advento da internet. A forma online de fazer jornalismo ganhou um elemento capaz de acrescentar à atividade não só uma modalidade diferente do que a praticada no impresso, no rádio e no telejornalismo, mas a própria forma de apresentar os fatos à sociedade. Rapidez, tempo real e atualização são os ingredientes que, por meio da globalização, chegam aos meios e veículos de comunicação, sugerindo mudanças nos critérios de seleção dos profissionais, na atuação do profissional e nos conhecimentos múltiplos exigidos pelo mercado de trabalho. A adequação é emergente e, mais do que isso, o reconhecimento deste novo jornalismo no campo acadêmico torna-se imprescindível.

Por mais que venham tecnologias e se consigam modificar os suportes com os quais trabalhamos, nossa relação com a palavra, com os fatos, com as opiniões, enfim, a necessidade de entender o mundo - e passar isso para o leitor - permanecerá. (COSTA, 1994, p. 1).

Sem a formação de mão de obra especializada, o jornalismo digital tem pouco futuro porque a pesquisa aplicada coordenada pelos profissionais do campo representa um pré-requisito para a geração da tecnologia que serve como mediadora para todas as relações dentro do jornal como sistema. (MIELNICZUK, 2003, p. 48).

O papel do jornalismo na atual sociedade da informação tem se mostrado mais dinâmico, ostensivo e reflexivo. A difusão de notícias, de forma instantânea, sem limites geográficos e com maior interatividade, tem sido um desafio para o profissional contemporâneo, ao mesmo tempo em que tem significado oportunidades no mercado de trabalho para atuar na profissão. As novas tecnologias, antes manuseadas prioritariamente no âmbito pessoal, passam a ser utilizadas como ferramentas eficazes para a atividade do jornalista. Com o avanço tecnológico, equipamentos como smartphones, tablets, notebooks, computadores e periféricos têm possibilitado ao jornalista, maior comodidade e rapidez na apuração, assim como condições melhores para realização de pesquisas e acesso às informações veiculadas pelo mundo. A conexão virtual modifica o olhar do profissional, seu texto, sua vida. Se antes os meios de 


\section{míDiA

comunicação de massa integravam as informações de um para um, agora, de forma abrangente, uma única tecnologia é capaz de apresentar imagens, textos, vídeos e sons a diversos públicos, imediata e simultaneamente, de um para todos.

A convergência de mídias é uma realidade que faz parte do cotidiano do profissional. Estes equipamentos que ligam o indivíduo ao mundo (um para todos, todos para todos, todos para um), por linha telefônica, satélite ou cabo, passam a fazer parte da realidade das redações das grandes e pequenas empresas jornalísticas.

Reportar as informações, em tempo real, é uma ideia que vinha rondando as agências de notícias americanas e europeias, desde o século XIX, tardando a chegar ao Brasil. Segundo Ferrari (2007, p. 13): "Nada mais natural que, com o surgimento da internet comercial, na década de 1990, [as informações] fossem as primeiras a alimentar o meio digital, detentor de espaço infinito e muita ânsia por conteúdo". As novas tecnologias estão introduzindo novos meios e métodos de transmitir informação. A busca de notícias imediatas é uma necessidade social contemporânea.

[...] Os novos portais de informações criaram leitores ávidos por informações escritas, ansiosos para ver reproduzida na tela impressa a instantaneidade do rádio, mas a tela de hipertexto carrega uma característica que o rádio não tem e que colocou em perigo a credibilidade do jornalismo nessa primeira década de existência da internet comercial: ela preserva a informação escrita ao longo do tempo, permite que o leitor acesse essas informações em outros momentos. (FERRARI, 2007, p. 13).

Nos primeiros anos de internet, algumas velhas lições da prática do jornalismo passaram por mudanças. A frenética busca por informações atuais, por parte do leitor, requereu a constante alimentação de conteúdo jornalístico. A atualização da informação passou a ser identificada a partir da observação das diferentes postagens de títulos e horários. No início dos anos 2000,

[...] portais como o IG (Portal de Notícias na Internet) prometiam publicar uma notícia por minuto, criando uma espécie de labirinto informacional não só na forma como as matérias eram dispostas, uma após a outra, numa tela com o fundo branco, que mais lembrava uma página de jornal, mas [...] esfacelava a técnica construtiva da notícia. (FERRARI, 2007, p. 14). 
À época, a celeridade da produção da notícia em muitas vezes antecipava a conclusão dos fatos, desconsiderando etapas relevantes na sua produção, como a imparcialidade e a checagem das informações. Desta forma, os conteúdos eram publicados de modo fragmentado, dificultando a sua compreensão e, ao mesmo tempo, comprometendo a credibilidade da mídia. Ainda segundo Ferrari (2007, p.14), "quem quisesse saber o que realmente [...] [havia acontecido] naquele dia, com todas as repercussões e facetas, teria que esperar o Jornal Nacional ou o jornal impresso da próxima jornada".

Essa nova modalidade de produzir e consumir a informação se refletiu na formação acadêmica e os Cursos de Comunicação tiveram que adequar seus currículos para a nova realidade. A formação profissional precisou familiarizar o graduando com as tecnologias que estavam surgindo no mercado, de modo a superar a lacuna entre o saber acadêmico e a prática profissional.

Em decorrência, os cursos de Jornalismo das universidades brasileiras passaram a promover melhorias em seus estúdios e laboratórios de informática, com a finalidade de criar ambientes de aprendizagem próximos aos da realidade das empresas jornalísticas. As exigências da prática profissional mobilizaram respostas no âmbito das Instituições de Educação Superior (IES), que não mediram esforços de publicidade e anúncios para captar seu público com ofertas de equipamentos de última geração, como tablets e notebooks, com conteúdos de ensino, para quem se matriculasse nelas.

No correr dos tempos, a profissão de jornalista tem passado por modificações tanto regulamentares quanto ocupacionais, que exigem das IES a constante atenção à qualidade da formação, o que pressupõe domínio tecnológico e conhecimento técnicocientífico atualizado. De acordo com Murad (1999), a internet trouxe desafios e oportunidades para a atividade do jornalismo nas redações:

A difusão das tecnologias digitais e a consequente convergência das áreas de comunicação, informática e telecomunicações estão transformando a atividade jornalística. As mudanças atingem a pesquisa, a produção e a difusão da informação. Possibilitam outras formas de relacionamento entre leitor e jornalista, exigindo a 
redefinição de técnicas. O novo quadro demanda, assim, alteração no perfil do profissional de informação. (MURAD, 1999, p.1).

O impacto das tecnologias e principalmente o advento da internet têm afetado também o jornalismo como negócio. A revista Newsweek, por exemplo, encerrou a sua versão impressa, em outubro de 2012, passando a disponibilizar apenas a versão digital. O Jornal do Brasil, pioneiro na versão online, e o jornal Estado do Paraná também optaram pelo fim da publicação impressa (PIO, 2012). O periódico americano The New York Times mostra tendência de diminuir o impresso, uma vez que sua versão digital é lida por mais de dois milhões de pessoas (BONIS, 2012).

De acordo com Rech (2012), anteriormente à globalização, os jornais tinham um modelo financeiro baseado em três pilares: circulação, comercialização e conteúdo. Hoje, as empresas jornalísticas buscam outras fontes de lucro, como a circulação digital, a venda de assinaturas digitais e a disponibilização de seus conteúdos na web.

A princípio, a mídia digital era utilizada meramente para reprodução de material originado pelas produções impressas e eletrônicas. Com o passar do tempo, a tendência foi estimular a criação e o aprimoramento de softwares desenvolvidos para dar maior autonomia aos usuários na elaboração e edição de textos, imagens e vídeos. Os usos do hipertexto e do hiperlink passaram a proporcionar nova forma de linguagem jornalística na construção do texto e na inserção de ilustrações para a geração de notícias, obrigando o profissional a se aperfeiçoar nestas tecnologias. Nos dias atuais, não basta criar um bom texto; é preciso pensar na elaboração de um texto que alie imagem, emoção e seduza o leitor. Frente a isto, impõe-se ao jornalista aprender a pensar em trígono, ter o texto, o audiovisual e a pós-edição, em mente, para que o leitor entenda e absorva a mensagem com o mesmo envolvimento com que acessa incansavelmente as redes sociais.

Para atuar no mercado, o profissional que se especializa no ambiente online precisa dominar não só os conhecimentos teóricos adquiridos na graduação, como também ter acesso às técnicas de uso dos equipamentos e o domínio das inovações tecnológicas que se apresentam no dia a dia. Além disso, é preciso que o ambiente acadêmico se recicle e passe a oferecer aos seus discentes, das áreas de comunicação e 


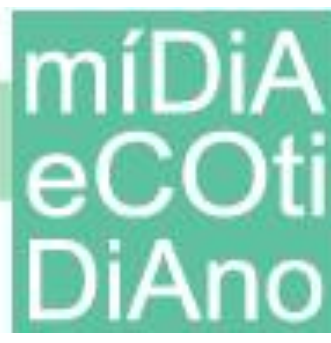

informação, meios para acesso às pesquisas científicas e prontidão para adquirir novos conhecimentos e habilidades essenciais. Da mesma forma, os professores que lecionam as disciplinas relacionadas às novas tecnologias nesta área, a exemplo de jornalismo digital ou online, devem acompanhar as inovações tecnológicas e a evolução das várias mídias utilizadas no mercado, pois são utilizadas como veículos de notícia. Usuários de redes sociais como Instagram, Facebook, Linkedin, por meio de tablets, smartphones e celulares são capazes de mobilizar multidões para determinado fim.

A cada momento, outros aplicativos são lançados para aprimorar o uso dos equipamentos e viabilizar as informações sem fronteiras, entre as sociedades.

Em particular, o Curso de Jornalismo desta IES oferecia em sua grade curricular a disciplina Projeto de Jornalismo Online. De acordo com o projeto pedagógico do Curso, a referida disciplina tinha por finalidade possibilitar ao graduando uma formação adequada para o seu bom desempenho profissional na área, contando com professores experientes em online e conhecedores da mídia digital.

Tendo exercido a docência superior na Instituição, de agosto de 2008 até fevereiro de 2014, a autora constatou que na IES pouco se desenvolvia o estudo do jornalismo online. No seu entendimento, havia carência na oferta de disciplinas que capacitassem o graduando para utilizar as ferramentas inerentes às novas tecnologias, assim como para formar o pensamento próprio à construção de textos digitais. A seu ver, a disciplina deveria possibilitar o estudo e vivências das tecnologias, considerando os seus vários recursos.

\section{Objetivo e justificativa do estudo}

O presente estudo teve por objetivo avaliar o mérito e o impacto da disciplina Projeto de Jornalismo Online, do Curso de Jornalismo de uma IES localizada no Rio de Janeiro, no que se refere à formação do graduando frente às exigências do mercado de trabalho.

A escolha desse tema, em um primeiro momento se justificou porque, à época, a autora fazia parte da equipe de professores que lecionava a disciplina em foco. Estava, portanto, comprometida em colaborar com a melhoria da formação acadêmica. Em 


\section{míDiA

outro, na qualidade de mestranda em Avaliação, considerou a possibilidade de desenvolver o estudo de modo a contribuir formativamente com a disciplina, que até então não havia sido avaliada.

Como decorrência da reflexão, observou que a avaliação assumiria o sentido de trazer contribuições para a formação acadêmica de jornalistas online, no âmbito das Instituições de Ensino. Foram preservadas, portanto, as importâncias didáticopedagógica, ética e social da avaliação e o compromisso com a adequada formação do futuro jornalista online para o mercado de trabalho.

\section{Formação e projeto pedagógico para a nova modalidade do jornalismo: o online}

É fato que os cursos universitários são criados pelas instituições de nível superior com o propósito de atender as demandas e exigências do mercado universitário. Procura, dessa maneira, reformular o seu projeto pedagógico, se adequando às inovações e tendências inerentes de cada profissão, para oferecer ao seu público alvo um produto diferenciado, em relação aos concorrentes. $\mathrm{O}$ presente trabalho analisou as três reformulações da instituição em pauta, objeto deste estudo, e se baseou nos dados recebidos. Verificou-se que a IES tomava como base o perfil profissional delineado pelo mercado, oferecendo, assim, um conjunto de disciplinas sequenciais, em grau de complexidade crescente que buscavam habilitar, com propriedade, o graduando para o exercício profissional nas respectivas áreas do impresso, do rádio e da televisão. Buscavam desta forma, oferecer disciplinas voltadas para estas modalidades, a fim de oportunizar aprendizagens que se assemelhariam às rotinas vivenciadas nas redações das empresas jornalísticas. Ou seja, para cada mídia, eram organizadas três disciplinas que habilitavam o graduando a atuar profissionalmente. Tais disciplinas contavam, inclusive, com laboratórios especiais para o exercício pleno da atividade - estúdio de rádio, de televisão e redação própria para o impresso.

No que tange às condições e criação de grade curricular própria para o desenvolvimento da modalidade Online, tal como as demais, a IES não desenvolveu 


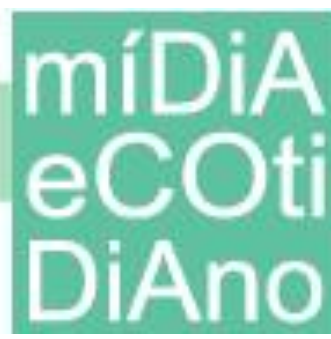

planejamento similar, caracterizando assim a lacuna na preparação do graduando à especialização desta recente modalidade do jornalismo.

A prática do jornalismo online é considerada como mais uma modalidade da função do jornalista, nos meios de comunicação. De um modo geral, as IES têm dado algum tratamento ao online, porém não têm se direcionado à criação de disciplinas que qualifiquem o graduando para este segmento, tal como acontece com os demais segmentos.

A disciplina não possuía pré-requisitos (disciplinas que instrumentalizam a construção de novas aprendizagens a partir dos conhecimentos mínimos que propiciam) ou co-requisitos (disciplinas que são ofertadas simultaneamente apresentando conteúdos afins que se integram e interagem uns com os outros). As aulas eram ministradas em laboratórios comuns, equipados com computadores com acesso à internet, oferecidos pela Instituição, e destinados aos docentes de cursos de diferentes áreas. Conforme o número de graduandos inscritos na disciplina, oferecia-se uma máquina para cada dois ou três alunos. As limitações de acesso às redes sociais, bem como a alguns sites restritos pela Instituição e a baixa velocidade de conexão eram fatores que prejudicavam o desenvolvimento de parte das aulas práticas.

\section{Procedimentos metodológicos}

Este capítulo apresenta os procedimentos metodológicos utilizados na elaboração do estudo e inclui a apresentação da abordagem e questões avaliativas, referências à construção e validação dos instrumentos utilizados, à coleta, análise e tratamento dos dados.

\section{Abordagem avaliativa}

A abordagem adotada no estudo decorre de dois conceitos centrais em avaliação: o de mérito e o de impacto pressupõe, portanto, uma avaliação formal. Sobre ela, Scriven (1967), esclarece que faz uso de métodos de pesquisa e julgamento, envolvendo a determinação de padrões relativos ou absolutos para apreciar a qualidade do objeto; 


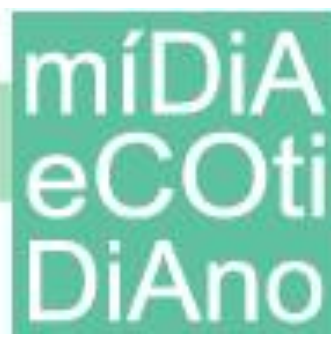

coleta informações relevantes sobre estes mesmos objetos e aplica padrões que irão determinar o valor, a qualidade, a utilidade, a eficácia ou sua importância. No caso, o processo avaliativo favorece o estabelecimento de recomendações com objetivo de otimizar o objeto de avaliação em relação ao(s) seu(s) propósito(s) futuro(s).

No caso deste estudo, propriamente, o impacto se refere às mudanças positivas conferidas à vida profissional dos egressos, após o seu envolvimento com o objeto de estudo.

\section{Questões avaliativas}

As questões avaliativas que nortearam o presente estudo foram as seguintes:

1) Quais as habilidades e competências que o graduado de jornalismo deve ter para trabalhar na área online?

2) Em que medida a disciplina Projeto de Jornalismo Online, no contexto da estrutura curricular do Curso de Jornalismo, possibilitou aos graduandos a devida preparação para atuar no mercado online?

3) Até que ponto a disciplina Projeto de Jornalismo Online qualificou o graduando para atuar na área do jornalismo online?

\section{Construção e validação dos instrumentos}

Para a construção dos instrumentos de avaliação, tomou-se como ponto de partida, o objetivo, as questões avaliativas e a experiência profissional da docente, de modo a orientar o estabelecimento dos indicadores a serem considerados na avaliação.

Em consonância ao objetivo do estudo, os instrumentos selecionados foram de dois tipos: roteiro de entrevista e questionário, que passam a ser caracterizados.

Considerando a necessidade de o estudo levantar dados a respeito da adequação da formação oferecida pela IES frente às exigências do mercado de Jornalismo Online e, ainda, identificar os critérios adotados por empresas de comunicação na seleção de profissionais para este campo de atuação, foram construídos, no estudo, dois roteiros de entrevistas estruturadas. O primeiro, direcionado ao especialista responsável pela seleção e recrutamento de jornalistas online, em empresa de comunicação de grande 


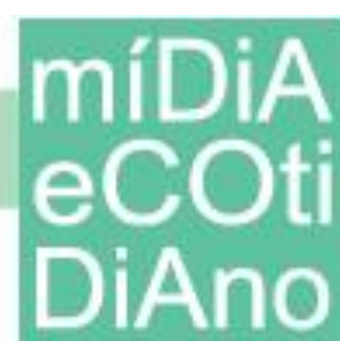

porte, pautou-se nas competências e habilidades consideradas essenciais para o exercício da profissão, e constou de seis questões. O segundo, destinado à gestora acadêmica da Instituição, incluiu oito questões relativas à atuação docente, à disciplina em questão, à infraestrutura (instalações e equipamentos) e à preparação acadêmica do egresso para o mercado de trabalho. $\mathrm{O}$ terceiro instrumento, um questionário misto, com 17 perguntas fechadas (estruturadas e dicotômicas) e duas abertas, dirigido aos 13 egressos. $\mathrm{O}$ instrumento buscou coletar informações da mesma natureza que a entrevista destinada à gestora: atuação do professor, disciplina, infraestrutura (instalações e equipamentos) e preparação do egresso para o mercado de trabalho, de modo a cotejar com o parecer do especialista.

Para fins de validação técnica e de conteúdo, os três instrumentos foram submetidos à apreciação de dois profissionais das áreas de Educação e Avaliação, que julgaram a verificação das características técnicas, além de atributos como clareza, pertinência, suficiência e ordem das questões.

\section{Aplicação dos instrumentos}

Em março de 2013, por meio de contato telefônico, a gestora da IES, coordenadora do Curso de Jornalismo, e o especialista foram convidados a colaborar com o estudo, cujo objetivo era avaliar o mérito e o impacto da disciplina Projeto de Jornalismo Online de modo a se contribuir para a construção de seu sentido acadêmico junto à comunidade docente da área. Ao especialista foi assegurada não só a preservação da sua identidade, mas também a da empresa onde trabalha. A aplicação do questionário se deu junto aos 13 egressos que concluíram a graduação na IES, entre os anos de 2010 e 2011, e atuavam no mercado de trabalho na condição de jornalista online. 


\section{míDiA

\section{Conclusões}

As conclusões do estudo avaliativo foram elaboradas tomando por base o conceito de triangulação proposto por Denzin (1973 apud MINAYO; ASSIS; SOUZA, 2005), significando a combinação e o cruzamento de pontos de vista.

A primeira questão avaliativa buscou saber "que critérios são utilizados atualmente na contratação de graduados em Jornalismo para atuar no setor online?". Na construção da resposta à questão, identificou-se serem critérios considerados no recrutamento e seleção de profissionais, além da formação acadêmica de qualidade, amplo conhecimento no uso das ferramentas utilizadas pelo online, pensamento e agilidade na construção da matéria para a mídia online, favorecido pelas condições acadêmicas necessárias ao seu aprendizado.

A opinião do especialista revelou claramente este ponto de vista. Na opinião da gestora, os critérios não foram explicitados, muito embora tenha dado a entender o predomínio da formação acadêmica (o saber) sobre o fazer, uma vez que entendia ser possível que a Instituição até poderia deixar de disponibilizar as condições técnicas adequadas para as atividades práticas. Para os egressos, os critérios requeridos pelo mercado, não foram considerados a contento pela IES, pois, depois de graduados, tiveram que buscar (in)formação prática e teórica para trabalhar no campo online.

A segunda questão avaliativa buscou saber "Em que medida a disciplina Projeto de Jornalismo Online, no contexto da estrutura curricular do Curso de Jornalismo, possibilitou aos graduandos a devida preparação para atuar no mercado online?". Ante a estrutura curricular oferecida pelo Curso, concluiu-se que a disciplina não pode preparar devidamente o graduando para o exercício profissional na área.

Em nível da formação acadêmica, a disciplina por si só seria insuficiente para garantir competências técnicas de elevada complexidade. Seria preciso que estivesse situada num contexto em que a grade curricular contivesse todo o conjunto de disciplinas necessário ao domínio dos saberes e fazeres do campo profissional. Além disto, tais disciplinas (obrigatórias, eletivas, pré-requisitos, correlatas) deveriam contar com infraestrutura compatível à formação na modalidade online, do mesmo modo que 


\section{míDiA \\ ecO

se procedeu em relação às disciplinas Projeto de Jornalismo Impresso, de Radiojornalismo e de Telejornalismo.

A gestora percebia que a estrutura curricular do jornalismo online, constituída por três disciplinas Novas Tecnologias da Comunicação, Produção de Website e Projeto de Jornalismo Online, esgotava o assunto online e, portanto, garantia a preparação adequada para atuar na área. Entendia que a disciplina, diferentemente de suas similares (Projeto de Jornalismo Impresso, Projeto de Radiojornalismo e Projeto de Telejornalismo), dispensava uma articulação curricular consistente porque perpassava direta e transversalmente as aprendizagens nas demais mídias. A maioria dos respondentes mostrou que os ensinamentos práticos da disciplina contemplaram somente noções básicas acerca da atividade jornalística online. Observaram que poderiam ter-se aprofundado mais na área, tal como ocorreu nas disciplinas relativas às modalidades de impresso, radiojornalismo e telejornalismo. Salientaram, ainda, que só tiveram acesso efetivo ao conhecimento do online ao serem absorvidos pelo mercado. Para o especialista, a adequada formação para a área requeria um conjunto de vivências e aprendizagens teórico-práticas compatíveis com as exigências do mercado, dando a entender que a limitação curricular da formação pudesse trazer prejuízos na preparação dos recém-formados.

A terceira questão avaliativa buscou saber, "até que ponto a disciplina Projeto de Jornalismo Online qualificou o graduando para atuar na área do jornalismo online?"

Os resultados da triangulação permitiram concluir que a disciplina qualificou parcialmente os graduandos para a área, pois, para exercer atividades online, depois de formados, os egressos tiveram que complementar a formação acadêmica, com cursos extracurriculares.

Segundo os egressos, os conhecimentos adquiridos na Instituição não foram suficientes para trabalhar em redações online, uma vez que tiveram que adquirir novas informações e habilidades, depois de formados. Responderam que, embora a atuação do docente tenha sido satisfatória, demonstrando domínio dos conteúdos, motivando os alunos para aprendizagem e referindo-se à própria experiência, ainda assim, não bastou para cumprir a lacuna deixada pela formação acadêmica. 


\section{míDiA

A gestora entendia que a disciplina bastava para qualificação do graduando para o mercado online, pois sua prática pedagógica dava-se no campo de integração dos conhecimentos comuns ao online, ao impresso, ao radiojornalismo e ao telejornalismo.

A observação do especialista sobre os requisitos necessários para trabalhar numa redação online (participação na faculdade de um projeto na modalidade online ou estágio em blog ou site do terceiro setor) não consistiu propriamente em resposta à pergunta. Contudo, contribuiu, indiretamente, mostrando que o não entendimento de que o jornalismo online é uma nova modalidade pode vir a comprometer a qualificação pretendida pela disciplina.

Em termos gerais, pode-se afirmar que, embora o mérito da disciplina tenha sido subtraído em sua essência, por não oferecer efetivas condições acadêmicas para a formação no campo do jornalismo online, o seu impacto se fez perceber junto ao contingente de egressos, que atuam na área específica. Mesmo reconhecendo limitações na formação inicial, estes jornalistas online buscaram implementar ações que os qualificassem para o pleno exercício de suas atividades.

\section{Recomendações}

Adotando a premissa de que nas instituições de ensino, o jornalismo online deva ser assumido não apenas como disciplina acadêmica, mas como campo emergente da atuação profissional, espera-se que as recomendações deste estudo avaliativo, contribuam em diferentes níveis para a melhoria da qualidade da formação acadêmica na modalidade Jornalismo Online. O estudo considera que disciplinas sobre jornalismo online sejam adequadas para habilitar plenamente o graduando para o exercício profissional da especialidade, tal como se preparam os discentes para as áreas do impresso, rádio e televisão. As recomendações estabelecidas são as que se apresentam:

- que sejam oferecidos cursos de formação continuada para os professores responsáveis pelo ensino das disciplinas pertinentes ao campo do Jornalismo Online, tendo em vista o seu aprimoramento didático-pedagógico e tecnológico.

- que, representantes da comunidade acadêmica dos Cursos de Jornalismo, disponham-se a avaliar a consistência interna e a adequação das grades 


\section{míDiA

curriculares do Curso, de modo a se apreciar, especialmente, a modalidade online, em termos da articulação e hierarquização das disciplinas, ementas, objetivos, conteúdos programáticos, infraestrutura, bibliografia, avaliação e especialização docente.

- que seja valorizada a criação de um espaço específico para as aulas práticas, tendo o ambiente características similares as de uma redação online.

- que, por iniciativa dos cursos de graduação, sejam ampliados os espaços acadêmicos e não acadêmicos objetivando a discussão sobre a qualidade da formação do jornalista, onde os resultados deste estudo avaliativo possam dar sua colaboração;

- que as IES que ofereçam o Curso de Jornalismo desenvolvam programa de formação continuada, destinado à atualização profissional dos egressos, possibilitando, a partir do estreitamento de vínculos com o mercado, ampliar a sua dimensão social, para além da graduação.

\section{REFERÊNCIAS}

BONIS, Gabriel. New York Times vai diminuir acessos gratuitos em site. Carta Capital, maio 2012. Disponível em: <http://www.cartacapital.com.br/internacional/new-yorktimes-vai-diminuir-acessos-gratuitos-em-seu-site>. Acesso em: 10 nov. 2013.

COSTA, Caio Túlio. Novas tecnologias, velhos dilemas. Sala de Imprensa; Palestra proferida em 23 nov. 94. Disponível em: $<$ http://www.bb.com.br/portalbb/page251,138,2514,0,0,1,6.bb?codigoMenu=5253\&cod igoNoticia $=6696 \&$ codigoRet $=5255 \&$ bread=1>. Acesso em: 27 abr. 2013.

FERRARI, Pollyana. Hipertexto e hipermídia: a novas ferramentas da comunicação digital. Rio de Janeiro: Contexto, 2007.

MIELNICZUK, Luciana. Sistematizando alguns conhecimentos sobre o jornalismo na web. In: MACHADO, Elias; PALACIOS, Marcos. (Org.) Modelos de jornalismo digital. Salvador: Grupo de Pesquisa de Jornalismo online da Universidade Federal da Bahia; Calandra, 2003.

MINAYO, Maria Cecília de Souza; ASSIS, Simone Gonçalves de; SOUZA, Edinilsa Ramos de (Org.). Conceito de triangulação por avaliação de métodos. In: 
Avaliação por triangulação de métodos: abordagem de programas sociais. Rio de Janeiro: Fiocruz. 2005.

MURAD, Angèle. Oportunidades e desafios para o jornalismo na Internet. Revista do Programa de Pós-graduação em Comunicação da Universidade Federal Fluminense, Rio de Janeiro, n. 2, $1999 . \quad$ Disponível em: <http://www.uff.br/ciberlegenda/ojs/index.php/revista/article/view/241/134>. Acesso em: 14 mar. 2013.

RECH, Marcelo. O recém-formado em jornalismo deve saber empreender. Observatório da Imprensa, São Paulo, ano 18, n. 721, nov. 2012. Entrevista concedida a Andrré Bürger. Disponível em: <http://observatoriodaimprensa.com.br/news/view/_ed721_o_recem_formado_em_jorn alismo_deve_saber_empreender>. Acesso em: 10 nov. 2013.

SCRIVEN, Michael. Evaluation Thesaurus, 4. ed. Thousand Oaks: Sage Publications, 1991. 